\title{
Penerapan Model Problem Based Learning Bantuan Media Video Terhadap Hasil Belajar Biologi Materi Sistem Ekskresi Kelas XI SMA Pencawan School Medan
}

\author{
${ }^{(1)}$ Winda Sari, S.Pd, ${ }^{(2)}$ Dra. Nurhasnah Manurung, M.Pd \\ Alumni Prodi Pend. Biologi ${ }^{(1)}$, Dosen Program Studi Pendidikan Biologi FKIP UISU (2) \\ windasari@gmail.com , nurhasnahmanurung@fkip.uisu.ac.id
}

\begin{abstract}
ABSTRAK
Penelitian ini bertujuan untuk mengetahui adakah pengaruh Penerapan model Peroblem Based Learning Dengan Bantuan Media Video Terhadap Hasil Belajar Siswa Pada Materi Ekskresi DI SMA Pencawan School. Penelitian ini dilaksanakan pada bulan April-Juli 2017. Penelitian ini menggunakan Metode eksperimen semu (Quasi experimen) dengan populasi penelitian adalah seluruh siswa di kelas XI SMA Pencawan School Medan Tahun Pembelajaran 2016/2017 yang berjumlah 61 siswa yang kemudian dijadikan sempel sebanyak 33 siswa dari kelas XI IPA 1 dengan cara pengambilan sampel secara acak (Random Sampling). Data yang dianalisis dalam penelitian ini adalah berupa test tertulis yaitu pre test dan post test pada materi ekskresi. Nilai rata-rata pre test sebelum model pembelajaran Peroblem Based Learning bantuan media video adalah 42,95 dan standar deviasi 8,21 maka seluruh siswa dinyatakan tidak tuntas (100\%). Dan rata-rata post test yang diperoleh setelah model yang diterapkan adalah 68,04 dan standar deviasi adalah 11,45. Berdasarkan nilai KKM 75 maka sebanyak 7 siswa (21\%) yang tuntas dan 26 siswa $(79 \%)$ belum tuntas. Berdasarkan uji hipotesis diperoleh $t_{\text {hitung }}=13,90$ sedangkan nilai $t_{\text {tabel }}=1,694$ jadi $t_{\text {hitung }}>\mathrm{t}_{\text {tabel}}$, maka $\mathrm{Ha}$ diterima dan $\mathrm{H}_{0}$ ditolak, dan dapat disimpulkan bahwa ada pengaruh signifikan menggunakan Penerapan Model Pembelajaran Problem Based Learning Bantuan Media Video Terhadap Hasil Belajar Biologi Materi Sistem Ekskresi Di Kelas XI SMA Pencawan School Medan.
\end{abstract}

Kata Kunci : Problem Based Learning Video, Belajar Biologi, Ekskresi

\begin{abstract}
This study aims to determine whether there is influence Implementation of Problem Based Learning Model with Media Video Assistance to Student Results on Excretory Material In SMA Pencawan School. This research was conducted in April-July 2017. This research used quasi experiment method with research population is all students in class XI SMA Pencawan School Medan Learning Year 2016/2017 which amounted to 61 students which then made as many as 33 students from Class XI IPA 1 By way of random sampling (Random Sampling). The data analyzed in this research is a written test that is pre test and post test on excretion material. The average value of pre test before applied model of Learning Peroblem Based Learning with Media Video Assistance is 42,95 and standard deviation 8,21 then all student are not complete $(100 \%)$. And the average post test is obtained after the applied model is 68.04 and the standard deviation is 11.45. Based on the value of KKM 75 then as many as 7 students (21\%) complete and 26 students (79\%) is not complete. Based on the hypothesis test obtained $t_{\text {count }}=13.90$ while the value $t_{\text {table }}=1.694$ so $t_{\text {count }}>t_{\text {table }}$, thus $\mathrm{H}_{\mathrm{a}}$ accepted and $\mathrm{H}_{0}$ rejected, and it can be concluded that there is significant effect of using Problem Based Learning Model With Media Media Aid to Biology Learning Outcomes at Material Excretion In Class XI SMA Pencawan School Medan
\end{abstract}

Keywords : Problem Based Learning Videos, Learning Biology, Excretion 
Sari W, Manurung N, : Penerapan Model Problem Based Learning Bantuan Media Video Terhadap Hasil Belajar Biologi Materi Sistem Ekskresi Kelas XI SMA Pencawan School Medan

\section{PENDAHULUAN}

\section{Latar Belakang}

Pada proses pembelajaran di kelas hingga saat ini masih juga ditemukan pengajar yang memposisikan siswa sebagai objek belajar, bukan sebagai individu yang harus dikembangkan potensi yang dimilikinya. Hal ini dapat mematikan potensi siswa. Dalam keadaan tersebut peserta didik hanya mendengarkan pidato guru di depan kelas, sehingga mudah sekali peserta didik merasa bosan dengan materi yang diberikan. Akibatnya, peserta didik tidak terlalu paham dengan apa yang baru saja disampaikan oleh guru, maka dalam peroses belajar di dalam kelas, harus ada penambahan cara mengajar yaitu dengan pemberian pembelajaran berbasis masalah yang berbeda dengan model pembelajaran yang lainnya, dalam model pembelajaran ini, peranan guru adalah menyodorkan berbagai masalah, memberikan pertanyaan, dan memfasilitasi investigasi dan dialog. Guru memberikan kesempatan kepada peserta didik untuk menetapkan topik masalah yang akan dibahas, walaupun sebenarnya guru telah menetapkan topik masalah apa yang harus dibahas. Hal yang paling utama adalah guru menyediakan perancah atau kerangka pendukung yang dapat meningkatkan kemampuan penyelidikan dan intelegensi peserta didik dalam berpikir. Proses pembelajaran diarahkan agar peserta didik mampu menyelesaikan masalah secara sistematis dan logis. Model pembelajaran ini dapat terjadi jika guru dapat menciptakan lingkungan kelas yang terbuka dan jujur, karena kelas itu sendiri merupakan tempat pertukaran ide-ide peserta didik dalam menanggapi berbagai masalah. Mata pelajaran Biologi di sekolah merupakan bagian dari sains, materi Biologi terdiri atas konsep serta teori yang memerlukan berbagai analisis serta fenomena yang memerlukan pemikiran yang luas. Namun proses pembelajarn biologi di sekolah juga masih hanya perkembangan sebatas kemampuan menghapal materi. siswa belum dibiasakan untuk memahami informasi dan menghubungkannya dengan kehidupan seharihari, serta mencari pemecahan masalah yang terlihat dalam materi. oleh karena itu penting diterapkannya keterampilan berpikir tinggi dalam proses pembelajaran sains Biologi. Biologi merupakan salah satu pelajaran yang diberikan pada jenjang SMA pada jurusan IPA. Dalam pembelajaran biologi selain paham terhadap konsep juga di tekankan pada pentingnya menggembangkan kemampuan berpikir dan memecahkan masalah. Berdasarkan hasil wawancara yang dilakukan peneliti dengan salah satu guru mata pelajaran Biologi yaitu Bapak Yusuf di SMA Pencawan School yang terletak di JL. Bunga Ncole Raya no.50 Medan. Berdasarkan data observasi nilai ujian tengah semester, pada sekolah Pencawan School Medan masih banyak siswa yang tidak memenuhi Kriteria Ketuntasan Minimum (KKM) yang diterapkan sekolah sebesar 75. Dari 61 siswa hanya $35 \%$ yang mendapat nilai 75 sedangkan $65 \%$ siswa mendapat nilai dibawah 75. Sekolah ini menggunakan Kurikulum Tingkat Satuan (KTSP). Adapun fasilitas yang ada di SMA Pencawan School Medan ialah ruang kelas, lab.Biologi, perpustakaan, lapangan sepak bola, tempat parkir, dan kantin sekolah. Adapun nilai KKM untuk mata pelajaran Biologi adalah 75. Pada tempat observasi awal ditemukan beberapa permasalahan dalam peroses pembelajaran, antara lain : (1) Pengajaran biologi yang diajarkan oleh guru di kelas masih diselenggarakan dengan menggunakan pembelajaran konvensional, (2) Siswa jarang atau hanya sebagian kecil yang mengajukan pertanyaan (3) Pendekatan antara guru dan siswa masih kurang, dikarenakan harus ada jarak antara guru dengan siswa agar siswa memiliki kesungkanan pada guru, (4) Pemakaian media dalam belajar yang masih terbatas, dikarenakan fasilitas seperti infokus yang belum mencukupi untuk semua kelas. Hal inilah yang menyebabkan rendahnya hasi belajar siswa terjadi, karena kurang aktifnya siswa dalam proses kegiatan belajar mengajar. Berdasarkan pemaparan masalah tersebut, usaha yang perlu dilakukan oleh guru untuk memperbaikinya adalah dengan pemilihan model pembelajaran yang tepat yaitu pelajaran yang merangsang kemampuan berpikir tinggkat 
tinggi, dengan suasana kondusif, terbuka, negosiasi, dan demokratis, sehingga belajar tidak berpusat hanya kepada guru, tetapi berpusat kepada siswa, agar lebih aktif dalam proses kegiatan belajar mengajar. Perlunya suatu strategi belajar yang dapat membantu siswa memahami materi ajar dan aplikasi dalam kehidupan sehari-hari, yaitu dengan pengunaan model yang lebih menarik bagi siswa agar proses dalam mengajar semangkin aktif. Model yang menuntut siswa memiliki kemampuan berpikir tingkat tinggi adalah model Problem Based Learning (PBL). Dengan mengunakan model berbasis masalah dapat membantu siswa aktif serta berpikir tinggi dalam kegiatan pembelajaran guna menggembangkan pola berfikir dari masalah yang dilihatnya, karena siswa di ajak untuk menyampaikan gagasan atau ide sehinnga diperoleh pemecahan atas permasalahan yang ada. Dari paparan di atas penelitian ini akan dikombinasikan dengan mata pelajaran Biologi khususnya materi ekskresi dengan menggunakan bantuan video, dimana saat video ditampilkan siswa mengidentifikasi permasalahan dalam materi serta mengemukakan pendapat tentang materi ajar, agar siswa lebih memahami permasalahan yang tampak dalam materi. Materi ekskresi mampu menimbulkan masalah yang dapat dicari solusinya, dengan menggunakan model Pembelajaran Berbasis Masalah diharapkan kompetensi dasar tujuan pembelajaran tercapai.

\section{Perumusan Masalah}

Berdasarkan uraian dalam latar belakang masalah, identifikasi masalah, maka dapat dirumuskan masalah penelitian yaitu sebagai berikut : Apakah ada pengaruh signifikan pada model Problem Based Learning bantuan media video terhadap hasil belajar siswa pada materi ekskresi di kelas XI SMA Pencawan School Medan Tahun Pembelajaran 2016/2017?

\section{Tujuan Penelitian}

Adapun tujuan penelitian adalah sebagai berikut:

1. Untuk mengetahui kemampuan dasar siswa sebelum menggunakan model Problem Based Learning bantuan media video pada materi ekskresi di kelas XI SMA Pencawan School Medan Tahun Pelajaran 2016/2017.

2. Untuk mengetahui penerapan model Problem Based Learning bantuan media video terhadap hasil belajar biologi siswa pada materi ekskresi di kelas XI SMA Pecawan School Medan Tahun Pembelajaran 2016/2017.

3. Untuk mengetahui peningkatan hasil belajar siswa setelah menggunakan model Problem Based Learning bantuan media video pada materi ekskresi di kelas XI SMA Pencawan School Medan Tahun Pembelajaran 2016/2017

\section{Manfaat Penelitian}

Dari hasil penelitian ini, maka diharapkan dapat memberi sejumlah manfaat yang positif, yakni antara lain:

1. Bagi Guru Biologi : Sebagai alat bantuan untuk memecahkan masalah yang sering ditemukan di dalam kelas, sehingga dapat melakukan inovasi dalam mengatasi berbagai permasalahan pembelajaran yang dihadapi dalam kelas.

2. Bagi Peneliti : Peneliti dapat menambah pengalaman, serta memperluas wawasan tentang pembelajaran, yang nantinya sebagai bekal diri menjadi pengajar dan pendidik yang akan mengajar nantinya.

3. Bagi Siswa : Sebagai bahan ajar yang lebih berkreasi yang bermanfaat dan menarik bagi peserta didik dalam peroses pembelajaran untuk meningkatkan hasil belajar siswa 
Sari W, Manurung N, : Penerapan Model Problem Based Learning Bantuan Media Video Terhadap Hasil Belajar Biologi Materi Sistem Ekskresi Kelas XI SMA Pencawan School Medan

\section{METODE PENELITIAN}

Metode penelitian yang digunakan dalam penelitian ini adalah Metode Quasi eksperimen atau yang disebut juga desain eksprimen semu. Yang mana adanya interaksi guru dengan siswa dan siswa dengan siswa dalam peroses pembelajaran . penelitian ini hanya melihat adakah pengaruh dari penerapan model Problem Based Learnig dengan berbantu video terhadap hasil belajar siswa . adapun desain penelitan yang digunakan adalah dengan membandingkan nilai pre test dan post test yang dilakukan pada kelas eksperimen.

\section{HASIL DAN PEMBAHASAN}

diketahui banyak kelas distribusi frekuensi nilai pre test berjumlah 6 kelas dan panjang kelas 6 setiap kelas. Pada angka persen siswa menunjukan bahwa kelas interval no. 4 yaitu 43-48, fi berjumlah 12 menunjukan angka persen paling tinggi yaitu 36.3\% sedangkan persen terendah kelas interval pada no 1 dan 6, fi berjumlah 3 dengan persen 9.09\%. Dari tabel tersebut kita juga dapat mengetahui $\sum$ fi.xi yaitu 1417,50, maka dapat diketahui nilai rata- rata pre test $\mathrm{x}=42,95$ simpangan baku $(\mathrm{S})=8,21$.

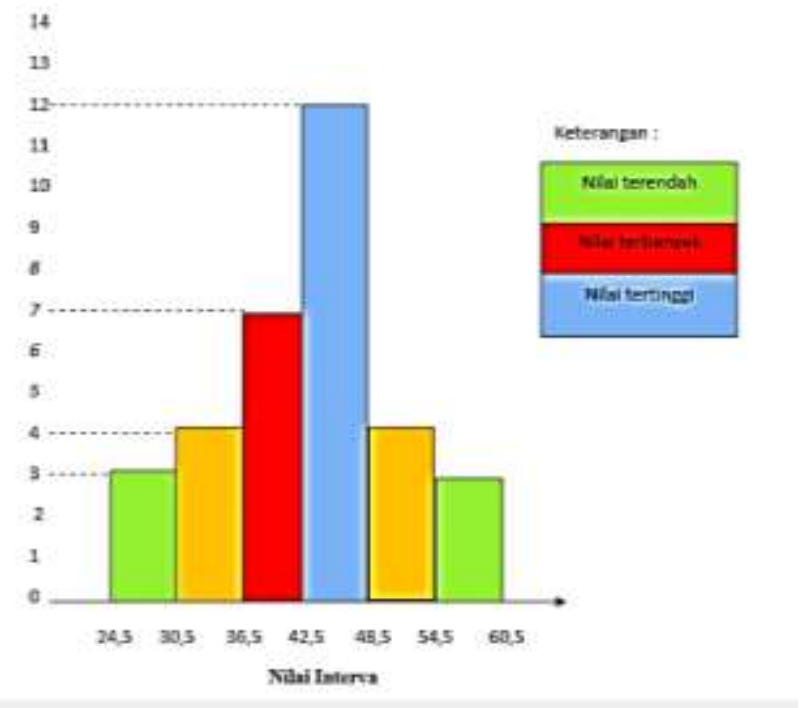

Berdasarkan gambar 3 dapat diketahui bahwa nilai yang diperoleh siswa kelas XI-IPA 1 pada saat pre test yaitu : banyaknya frekuensi nilai terendah yang diperoleh siswa yaitu berada pada nilai interval 24,5 -30,5 dan 54,5 - 60,5 dengan jumlah frekuensi 3 . Banyaknya frekuensi nilai terbanyak berada pada nilai interval 36,5 - 42,5 dengan jumlah frekuensi 7. Dan banyaknya nilai tertinggi berada pada nilai 42,5 - 48,5 dengan jumlah frekuensi 12. Berdasarkan nilai KKM yang ditetapkan pihak sekolah tersebut dengan melihat hasil belajar siswa pada Tabel 6 di atas dapat diketahui bahwa terdapat 7 orang siswa (21\%) yang tuntas dan 26 orang (79\%) tidak tuntas. Kemudian dapat diketahui banyak kelas distribusi frekuensi nilai post test berjumlah 6 kelas dan panjang kelas 6 setiap kelas. Pada tabel tersebut kita juga dapat menggetahui $\sum$ fi.xi yaitu 2245,00 , maka dapat diketahui nilai rata-rata post test $\mathrm{x}=68,04$ simpangan baku $(\mathrm{S})=11,45$. Uji Normalitas dapat diketahui hasil perhitungan dengan jumlah siswa 33 data pre test diperoleh $\mathrm{L}_{\text {hitung }}=0,1287$ yang merupakan nilai terbesar yang diperoleh dari selesih Fzi dengan $\mathrm{S}(\mathrm{Zi})$. $\mathrm{L}_{\text {tabel }}$ dengan $\mathrm{n}=33$ pada taraf nyata $\alpha=0,05$ diperoleh $\mathrm{L}_{\text {tabel }}=\frac{0,886}{\sqrt{33}}=$ 0 ,149. Dengan demikian $\mathrm{L}_{\text {hitung }}<\mathrm{L}_{\text {tabel }}(0,1287<0,1542)$, maka dapat dinyatakan bahwa hasil belajar siswa pada pre test berdistribusi normal pada materi Ekskresi yang diberikan di SMA Pencawaan School Medan Tahun Pembelajaran 2016/2017. Kemudian dapat diketahui hasil 
Sari W, Manurung N, : Penerapan Model Problem Based Learning Bantuan Media Video Terhadap Hasil Belajar Biologi Materi Sistem Ekskresi Kelas XI SMA Pencawan School Medan

perhitungan dengan jumlah siswa 33 data post test diperoleh $\mathrm{L}_{\text {hitung }}=0,0478$ yang merupakan nilai terbesar yang diperoleh dari selisih FZi dengan $\mathrm{S}(\mathrm{Zi})$. $\mathrm{L}_{\text {tabel }}$ dengan $\mathrm{n}=35$ pada taraf nyata $\alpha=0,05$ diperoleh $\mathrm{L}_{\text {tabel }}=0,1542$. Dengan demikian $\mathrm{L}_{\text {hitung }}<\mathrm{L}_{\text {tabel }}(0,1146<0,149)$, maka dapat dinyatakan bahwa hasil belajar siswa pada post test berdistribusi normal pada materi Ekskresi yang diberikan di SMA Pencawan School Medan Tahun Pembelajaran 2016/2017. Uji Homogenitas Uji homogenitas varians diuraikan untuk menguji kesamaan variabel menggunakan uji $F$ (Varians terbesar dan terkecil), dari perhitungan uji $\mathrm{F}$, maka diperoleh $\mathrm{F}_{\text {hitung }} 1,39$ untuk $\mathrm{n}=33$, kemudian nilai dikondisikan dengan nilai tabel distribusi $\mathrm{F}$, dengan $\alpha=0,05 \mathrm{dan} \mathrm{dk}=\mathrm{n}-1(33-1=32)$, karena harga $F_{\text {tabel }}$ tidak ada dalam tabel distribusi $F$, maka untuk mencari $F_{\text {tabel }}$ dilakukan dengan cara interpolasi. Dari perhitungan diperoleh $\mathrm{F}_{\text {tabel }}$ sebesar, 1,80. Dari perhitungan tersebut dapat diketahui bahwa $\mathrm{F}_{\text {hitung }},<\mathrm{F}_{\text {tabel }}(1,39<1,80)$ sehingga dapat disimpilkan bahwa kelas XI-IPA 1 adalah homogen. Uji Hipotesis memperoleh hasil distribusi untuk $\alpha=0,05$ dan $\mathrm{dk}=\mathrm{n}-1$ (33-1 = 32) diperoleh $t_{\text {tabel }} 1,649, t_{\text {hitung }}=13,90$. Dengan demikian $t_{\text {hitung }}>t_{\text {tabel }}$ atau 13,90 $>1,649$. Berdasarkan data diatas maka hipotesis alternatif diterima dan hipotesis nihil ditolak. Dengan demikian dapat disimpulkan ada pengaruh yang signifikan Model Problem Based Learning bantuan media video terhadap hasil belajar siswa pada materi Ekskresi di kelas XI-1 SMA Pencawan School Medan Tahun Pembelajaran 2016/2017. Peningkatan yang belum terlalu maksimal ini dikarenakan waktu dalam pengajaran yang terlalu singkat, Peneliti yakin bahwa apabila waktu dalam mengajar cukup lama maka peningkatan dari hasil belajar menggunakan model Problem Based Learning Ini pasti akan jauh lebih meningkat dari awal sebelum menggunakan model, apalagi peroses belajar yang mengunakan bantuan video menambah pemahaman dalam melihat isi materi ajar, sehingga siswa semangkin memahami isi dari materi pembelajaran yang akan di sampaikan dalam pembelajaran.

\section{DAFTAR PUSTAKA}

Arikunto, Suharsimi. 2012. Prosedur Penelitian suatu Pendekatan Praktik. Jakarta: Rineka Cipta

Biologi wordpress: Model Pembelajaran SSCS. Diambil dari https://biologi21. wordpress.com/2010/10/12/model-pembelajaran-sscs/ diakses tgl 20 Maret 2017 pukul 19.00

Chin, Christine. 2010. Promoting Higher Cognitive Learning In Science Through A Problem-Solving Approach. Singapore: National Institute of Education, REACT))

Hewindati, Yuni Tri. 2004. Pemahaman Murid Sekolah Dasar terhadap Konsep IPA. Jakarta: Lembaga Pendidikan Universitas Terbuka

Ibrahim, Nurdin. 2003. Pemanfaatan Tutorial Audio Interaktif. Jurnal Pendidikan dan Kebudayaan No. 044, Tahun ke-9, September 2003

Jauhari, Mohammad. 2011. Implementasi Paikem dari Behavioristik sampai Konstruktivistik. Jakarta: Prestasi Pustaka Publisher

Kartono, Kartini. 2003. Bimbingan Belajar di SMA dan Perguruan Tinggi. Jakarta: Rajawali

Koster, Wayan. 2000. Faktor-faktor yang Berpengaruh terhadap Hasil Belajar Siswa SLTPN di Jakarta. Jakarta: Mimbar Pendidikan 
Sari W, Manurung N, : Penerapan Model Problem Based Learning Bantuan Media Video Terhadap Hasil Belajar Biologi Materi Sistem Ekskresi Kelas XI SMA Pencawan School Medan

Kusmawan, Udan. 2013. Values Infusion Into Scientific Actions In Environmental Learning: A Preliminary Research Report (Australia: The University of Newcastle, 2013)

Mudzakir, Ahmad. 2002. Psikologi Pendidikan. Bandung: Pustaka Setia

Mulyasa, E. 2003. Kurikulum Berbasis Kompetensi, Konsep, Karakteristik, Implementasi dan Inovasi. Bandung: Remaja Rosdakarya

Popham, W. James dan Eval L. Baker Penerjemah T. Amirul Hadi. 2001. Teknik Mengajar secara Sistematis. Jakarta: Rineka Cipta

Purwanto, M. Ngalim. 2002. Psikologi Pendidikan. Bandung: Remaja Rosdakarya

Rifa'i, Veithzal. 2003. Upaya Meningkatkan Hasil Belajar Kepemimpinan Peserta Diklat Spama Survei di Diklat Depkes (2000). Jakarta: Jurnal Pendidikan dan Kebudayaan, No. 40 Tahun ke-9, Januari 2003

Slameto. 2003. Belajar dan Faktor-faktor yang Mempengaruhinya. Jakarta: Rineka Cipta

Sudjana, Nana. 2000. Proses Belajar Mengajar. Bandung: Tarsito

Sudjana. 2010. Metoda Statistika. Bandung: Tarsito

Sugiyono. 2012. Metode Penelitian Pendidikan, Pendekatan Kuantitatif, Kualitatif, dan $R \& D$. Bandung: Alfabeta

Sukmadinata, Nana Saodih. 2003. Landasan Psikologis Proses Pendidikan. Bandung: Remaja Rosdakarya

Suryabrata, Sumadi. 2002. Psikologi Pendidikan. Jakarta: Raja Grafindo Persada

Syah, Muhibbin. 2004. Psikologi Pendidikan dengan Pendekatan Baru. Bandung: Remaja Rosdakarya

Syah, Mulyadi. 2004. Psikologi Belajar. Jakarta: Raja Grafindo Persada

Tim Penulis PEKERTI Bidang MIPA. 2001. Hakikat Pembelajaran MIPA dan Kiat Pembelajaran Biologi di Perguruan Tinggi. Jakarta PAU, PPAI Universitas Terbuka

Wahyudi. 2002. Tingkat Pemahaman Siswa terhadap Materi Pembelajaran IPA. Jurnal Pendidikan dan Kebudayaan. Vol 8 No. 036, Mei 2002

Yusmaidah. 2000. Peningkatan Hasil Belajar Siswa dengan Menggunakan Media Peta. Majalah Pelangi Pendidikan

Nurhayati, Nunung. 2009. 1700 Bank Soal Bimbingan Pemantapan Biologi SMA. Bandung: Yrama Widya 